\title{
Retrospective study of 108 cases of botulism in Poitiers, France
}

\author{
P. ROBLOT, F. ROBLOT, J. L. FAUCHĖRE*, A. DEVILLEGER, R. MARÉCHAUD, J. P. BREUX, \\ G. GROLLIER* and B. BECQ-GIRAUDON
}

Service de Médecine Interne et Maladies Infectieuses and "Laboratoire de Microbiologie A, Hôpital La Milétrie, 350 Avenue Jacques Coeur, 86021 Poitiers Cedex, France

\begin{abstract}
Summary. Botulism, a food-borne toxin-mediated disease caused by Clostridium botulinum is still a common disease, which is most frequent in the rural environment; 108 cases, 66 males and 42 females, average age 32 years, were recorded from 1965 to 1990 in the infectious disease department of the University Hospital of Poitiers (France). In $83 \%$ of patients, the food responsible was home-cured ham. Mean incubation time was 3.4 days; digestive symptoms were observed in $93 \%$ of cases, ocular symptoms in $92 \%$ and urinary tract dysfunction in $22 \%$. A scale of severity was used to classify the patients into those suffering from severe (6), intermediate (50) and mild (52) forms of the disease. Botulinum toxin type B was found in $36(52 \%)$ of 69 blood samples and in $41(51 \%)$ of 81 samples of the suspected food. From 1965 to 1976,44 patients were treated with both toxoid and heterologous equine serotherapy. Since 1976, 29 patients have been treated with guanidine hydrochloride ( $35 \mathrm{mg} / \mathrm{kg}$ daily) and 35 patients with guanidine hydrochloride plus heterologous serotherapy. All 108 patients recovered without any sequelae.
\end{abstract}

\section{Introduction}

Botulism is a widespread disease caused by the ingestion of a neurotropic exotoxin produced in contaminated food by Clostridium botulinum. It remains infrequent but is widely feared because it can be severe and is potentially lethal. The diagnosis can be straightforward but treatment is poorly defined. In the USA, 766 outbreaks representing 1961 cases have been recorded in the last 77 years; 289 of these outbreaks have occurred between 1949 and 1976 and 355 cases were recorded between 1977 and 1984..$^{1,2}$ The overall incidence of the disease in the USA is stable with 0.125 cases $/ 100000$ population overall, but large regional variations occur with the highest incidence $(8 \cdot 4 / 100000)$ in Alaska. ${ }^{2}$ Many countries have also reported it $;^{3,4-6}$ the highest incidence is in Poland and China. In France, the average number of cases reported varies from year to year but the epidemiological data are unreliable because of under-reporting: 22 cases were reported annually from 1966 to 1970 , 70.8 cases from 1971 to 1978 and 28 cases from 1979 to $1988 .{ }^{7}$ The mean incidence is estimated at $0 \cdot 12$ cases/100000 inhabitants.

The disease is more common in men than in women; $60 \%$ of patients in the USA are men with an average age of 40 years. $^{2}$ In France, in 1987 and 1988, there were 26 male and 23 female patients aged $13-66$ years. ${ }^{7}$ The disease also occurs in infants, ${ }^{8,9}$ but the mech- anism of the disease is different and follows intestinal infection with $C$. botulinum. In adults, botulism remains mainly food-borne, ${ }^{1,10,11}$ possibly favoured by underlying intestinal disease, ${ }^{9,10}$ but reports of botulism caused by inoculation ${ }^{12}$ are becoming more frequent, particularly among drug addicts. ${ }^{13}$

There are five antigenically distinct types of botulinum toxin, A-E. In the USA the toxin is type A in $60 \%$ of cases, type $\mathrm{B}$ in $30 \%$ and type $\mathrm{E}$ in $10 \% ; 90 \%$ of type E botulism occurs in Alaska. ${ }^{2}$ In most of the cases observed in USA and France, the contaminated foods involved are home-preserved vegetables (type A toxin) meat (type B) or fish (type E). ${ }^{2,7,14,15}$ In France, type B toxin has been identified in $97 \%$ of cases, the rest being of type A or, rarely, of type E. ${ }^{16}$ Pork, especially home-cured ham, is the responsible food in $93 \%$ of the cases in France. ${ }^{7,17}$

Biological confirmation of diagnosis can be obtained by detection of the toxin in serum or stool samples or by isolation of the causative organism from the food. Demonstration of the toxin can be done by an ELISA test or by seroneutralisation in mice, which is the standard reference method. ${ }^{18}$

The treatment of botulism remains poorly standardised, particularly for the mild forms, which are by far the most common. Serotherapy is the only specific treatment but its use is controversial. An alternative treatment with guanidine has been proposed but, although its safety is well established ${ }^{19}$ this treatment is not universally accepted because its effectiveness has not been clearly demonstrated. 
In this retrospective report, we describe 108 cases of botulism from the University Hospital of Poitiers, seen over a 25-year period and treated with either serotherapy or guanidine. A scheme for evaluating severity based on the main clinical signs is proposed.

\section{Patients and methods}

\section{Patients}

The study comprised 108 patients admitted to the Infectious Diseases Department, University Hospital of Poitiers, between Jan. 1966 and Dec. 1990. The diagnosis of botulism was based on epidemiological data and on a clinical score of severity. The main clinical symptoms and signs found in botulism ${ }^{2,4}$ were used to establish a clinical score of severity which permitted classification of the disease into three forms: mild, intermediate or severe (table I). Each symptom or sign was scored for 1 point. The points numbers 1-7 defined the mild form (score $\leqslant 3$ ) and intermediate forms (score 4-7); the last two points defined severe forms (score 8-9, or any including the last two points). Five patients with known disorders that may have interfered with clinical evaluation were excluded from the study.

\section{Methods}

Botulinum toxin was detected in serum or suspected food by the mouse seroneutralisation test. Briefly, one part of the suspected food was homogenised with an equal volume of buffer ( $\mathrm{pH} 6.8$, containing agar, sterile water and disodium phosphate) and centrifuged at $2000 \mathrm{~g}$ for $15 \mathrm{~min}$. The serum or supernate of homogenised food were separated into four parts of $2 \mathrm{ml}$ each; three were neutralised with a specific equine antiserum (anti-A, -B or -E) and one was not neutralised. One $\mathrm{ml}$ of each sample was then injected intraperitoneally into a mouse. After 2-6 h, the mice inoculated with material containing un-neutralised botulinum toxin developed a paralytic disease and died within $24-36 \mathrm{~h}$, the others survived without disease.

\section{Results}

Between Jan. 1966 and Dec. 1990, 108 cases met the inclusion criteria. The patients comprised $66(61 \%)$ males and $42(39 \%)$ females aged 5-70 years (median 32 years). The suspected causative food was ham in $83 \%$ of cases and, in all but one case, the ham had been home-cured. The mean incubation period was 3.45 days (range $0.5-16$ days, median 3.2 days) and the mean time to diagnosis was 7.11 days (range 3-32 days, median $6 \cdot 1$ days). According to the clinical criteria (table I), six (5.6\%) patients were classified as suffering from severe disease, $50(46 \%)$ from intermediate disease and $52(48 \%)$ from a mild form.

\section{Clinical features}

The presenting symptoms (table II) were restricted to the gastrointestinal tract in 41 cases $(47 \%)$ and included diarrhoea, abdominal pain, nausea, vomiting and, sometimes, constipation. Ocular symptoms and dry mucosa syndrome (dryness of the mouth, dysphagia, dysphonia, drying of the lacrymal secretions) occurred first in $18(17 \%)$ and $17(16 \%)$ cases, respectively. In seven cases, both digestive and ocular symptoms and, in 15 cases, both digestive and dry mucosa syndrome, occurred together.

At the fully developed stage of disease (tables II and III) dry mucosa syndrome was observed in 102 patients $(95 \%)$, and was associated with dysphagia $(95$ cases, $88 \%$ ), or deglutition problems ( 31 cases, $29 \%$ ). Strawberry tongue, probably due to sicca syndrome, sometimes with thrush, was also observed (16 cases). Dysphonia occurred in 17 cases $(16 \%)$.

Ocular symptoms were observed in $100(92 \%)$ cases comprising loss of accommodation associated with mydriasis (64 cases, $59 \%$ ), diplopia ( 18 cases, $17 \%$ ) or ptosis (eight cases, $7 \%$ ), or a combination of these. Digestive symptoms included persistent constipation ( 78 cases, $72 \%$ ) and abdominal pain ( 38 cases, $35 \%$ ). In one case, intestinal obstruction with fever occurred, but this resolved spontaneously.

Table I. Proposed severity scores for classification of botulism

\begin{tabular}{lcc}
\hline Clinical form & Score & $\begin{array}{c}\text { Number of patients } \\
(\%)\end{array}$ \\
\hline Mild & $\leqslant 3$ & $52(48)$ \\
Intermediate & $4-7$ & $50(46 \cdot 2)$ \\
Severe & $8-9$ & $6(5 \cdot 6)$ \\
Total & & $108(100)$
\end{tabular}

Scores were determined by the number of the listed symptoms observed. Mild and intermediate forms are defined by the presence of, respectively, $\leqslant 3$ and $3 \leqslant 7$ of the points numbers $1-7 ; \geqslant 8$ points or points numbers 8 or 9 , define a severe form of the disease. 1 , Problems of accommodation (visual impairment). 2, Dryness of the mouth (dry syndrome). 3, Retarded intestinal transit. 4, Dysphagia liquid and/or solid. 5, Persistent constipation. 6, Urinary symptoms. 7, Asthenia. 8, Respiratory paralysis. 9, Peripheral paralysis + impossibility of oral feeding.

Table II. Frequency of clinical symptoms in relation to the stage of the disease

\begin{tabular}{lcc}
\hline & Number (\%) of patients at \\
\cline { 2 - 3 } Symptoms & $\begin{array}{c}\text { initial } \\
\text { stage }\end{array}$ & $\begin{array}{c}\text { fully } \\
\text { developed } \\
\text { stage }\end{array}$ \\
\hline Digestive alone & $51(47)$ & $1(0.9)$ \\
Ocular alone & $18(17)$ & $3(2 \cdot 8)$ \\
Dry mucosa alone & $17(16)$ & $5(4 \cdot 6)$ \\
Digestive and ocular & $7(6.5)$ & $2(1.9)$ \\
Digestive and dry mucosa & $15(14)$ & $2(1.9)$ \\
Ocular and dry mucosa & 0 & $22(20)$ \\
Digestive and dry mucosa & 0 & $73(68)$ \\
and ocular or others & & \\
\hline
\end{tabular}


Table III. Clinical features of botulism in five studies, as indicated by the percentage of patients with typical symptoms

\begin{tabular}{|c|c|c|c|c|c|}
\hline \multirow[b]{2}{*}{ Symptoms } & \multicolumn{5}{|c|}{ Percentage of patients with symptoms in the following studies } \\
\hline & $\begin{array}{l}\text { MacDonald } \\
1985^{13} \text { (Type } \\
\text { A, } 28 \text { cases) }\end{array}$ & $\begin{array}{l}\text { Lecour } 1988^{4} \\
(30 \text { cases, } \\
\text { incubation } \\
\text { period } \\
10 \mathrm{~h}- \\
6 \text { days })\end{array}$ & $\begin{array}{c}\text { St-Louis } \\
1988^{23} \\
\text { (33 cases, } \\
\text { incubation } \\
\text { period } \\
2 \cdot 3 \text { days) }\end{array}$ & $\begin{array}{c}\text { Wainwright } \\
1988^{2} \\
\text { (133 cases) }\end{array}$ & $\begin{array}{c}\text { Present } \\
\text { study } 1990 \\
\text { (108 cases, } \\
\text { incubation } \\
\text { period } 3 \cdot 5 \\
\text { days) }\end{array}$ \\
\hline \multicolumn{6}{|l|}{ Ocular } \\
\hline Visual problems & 90 & 100 & 88 & 93 & 93 \\
\hline Diplopia & 78 & 30 & 73 & 66 & 17 \\
\hline Ptosis & $\ldots$ & 60 & $\ldots$ & 59 & $7 \cdot 4$ \\
\hline Mydriasis & $\ldots$ & 93 & $\cdots$ & 63 & 59 \\
\hline \multicolumn{6}{|l|}{ Bucco-pharyngeal } \\
\hline Dry mouth & 70 & 100 & 85 & 90 & 95 \\
\hline Dysphagia & 78 & 90 & 91 & 76 & 88 \\
\hline Dysphonia & 60 & 50 & 82 & 44 & 16 \\
\hline \multicolumn{6}{|l|}{ Digestive } \\
\hline Constipation & $\ldots$ & 100 & 48 & 42 & 72 \\
\hline Inaugural diarrhoea & $\ldots$ & 23 & 21 & $\ldots$ & 62 \\
\hline Nausea \pm vomiting & 37 & 40 & 59 & 88 & 62 \\
\hline Urinary retention & $\ldots$ & 27 & $\ldots$ & $\ldots$ & 18 \\
\hline \multicolumn{6}{|l|}{ Miscellaneous } \\
\hline Dizziness & 60 & 43 & 73 & 44 & $\ldots$ \\
\hline $\begin{array}{l}\text { Asthenia and muscular } \\
\text { weakness }\end{array}$ & 36 & 100 & $\cdots$ & 81 & 97 \\
\hline Respiratory problems & $\ldots$ & 20 & $\ldots$ & 66 & $5 \cdot 6$ \\
\hline
\end{tabular}

Table IV. Results of toxin determinations in serum and food by mouse inoculation test in 108 cases of botulism

\begin{tabular}{l|rrrr}
\hline \multirow{2}{*}{ Toxin in blood } & \multicolumn{4}{|c}{ Toxin in food } \\
\cline { 2 - 5 } & Positive & Negative & ND & Total \\
\hline Positive & 19 & 9 & 9 & 37 \\
Negative & 8 & 14 & 9 & 31 \\
ND & 22 & 10 & 8 & 40 \\
Total & 49 & 33 & 26 & 108 \\
\hline
\end{tabular}

ND, not done.

Table V. Treatment of 108 patients with botulism

\begin{tabular}{lc}
\hline \multicolumn{1}{c}{ Treatment } & $\begin{array}{c}\text { Number of patients } \\
(\%)\end{array}$ \\
\hline $\begin{array}{l}\text { Antiserum } \\
\text { (with or without toxoid) }\end{array}$ & $43(40)$ \\
Guanidine alone & $33(31)$ \\
Guanidine and antiserum & $31(29)$ \\
No treatment & $1(1)$ \\
Total & 108 \\
\hline
\end{tabular}

Urinary tract symptoms included dysuria or bladder paresis (19 cases, $18 \%$ ); seven cases of acute urinary retention required catheterisation. General symptoms consisted of asthenia and anorexia; fever was observed in only three cases.

In 10 cases, electromyography was performed; in three cases a presynaptic neuromuscular block was demonstrated.

\section{Toxin detection}

In 100 cases, serum or food samples were examined for toxin (table IV). Confirmation of the diagnosis was obtained in 67 patients by analysis of the suspect food (30 cases), or by the demonstration of circulating toxin (18 cases), or both (19 cases). The toxin identified was always of type B. Results of toxin assays in serum and food were concordant in 33 cases (both positive in 19 cases, both negative in 14 cases). The results from the examination of serum and food samples were discordant in 17 cases (serum positive and food negative in nine cases, serum negative and food positive in eight cases). In 17 cases multiple blood samples were obtained; in seven of these the toxin assay on the second sample gave negative results, but in 10 cases circulating toxin was found 5-43 days (mean 13.2 days) after the first determination. Five patients had received equine antitoxin between the first and the second assays; in two cases the result of the second assay for toxin was negative, in three cases it was positive.

\section{Treatment}

Treatment of the 108 patients is summarised in table $V$. The antiserum was of equine origin, the toxoid was a formol-inactivated toxin and guanidine was used in a syrup form. Apart from some local reaction at the point of injection, no severe reactions were observed with the antiserum. There were signs of intolerance with the use of guanidine in two cases: psychomotor agitation in one case and muscular pain in the other. These side effects disappeared $48 \mathrm{~h}$ after reducing the 
dose. All patients recovered without sequelae. The mean time for resolution was 21 days from the time of admission. Only two patients had to be admitted to the intensive care unit and required ventilatory assistance, one for inhalation pneumonia and the other for respiratory muscular paralysis.

Additional measures required were: nursing care, suspension of oral feeding, parenteral nutrition or nutrition by gastro-duodenal tube, humidification of the buccal and pharyngeal mucosa by spraying, oral amphotericin B to prevent fungal infections, the use of artificial tears and prevention of decubitus complications.

\section{Discussion}

The 108 patients reported here represent only a proportion of the cases in our geographic area. The exact proportion cannot be known because some patients would have been hospitalised in other hospitals in the geographic area, and some patients with mild forms of botulism are not admitted to hospital. It appears that the diagnosis is often missed. Although the incidence of botulism in France is similar to that in the USA, certain regions such as PoitouCharentes stand out for their unusually high incidence. This may be related to traditional home-made food practices, e.g., hams are prepared without brine. It can be estimated that there is an average of 4.15 cases of botulism/year in the French department of the Vienne.

In our study, the observed clinical pictures agreed with published descriptions ${ }^{2,4,20-23}$ (table III). The incubation period varied from 1 to 16 days. The initial period was short and characterised in $>50 \%$ of cases by digestive disorders followed by bilateral and symmetrical paralytic ocular manifestations associated with secretory problems. Oropharyngeal symptomsdysphagia, which may be total in severe disease, dysphonia and drying syndrome (dryness of the mouth, drying of salivary secretions, etc)-occurred most frequently. ${ }^{2,20}$ Ocular symptoms-acute presbyopia caused by paralysis of accommodation, mydriasis, diplopia and dryness of lacrymal secretionwere almost as common. ${ }^{24}$ Persistent constipation, urinary tract disorders (dysuria and urine retention), serious respiratory problems caused by paralysis or deglutition dysfunction were less frequent, ${ }^{21,22}$ asthenia, arterial hypotension and vertigo, reported by several authors, ${ }^{20}$ were not observed in our patients.

Usual biological parameters revealed no specific or significant abnormalities. Electromyography showed a presynaptic block which was neither constant nor specific $^{4,25,26}$ but which may be prognostically useful in severe forms of the disease. However, the results of laboratory tests did not change the therapy, which was based on the assessment by clinical examination. ${ }^{2}$

Usually, the diagnosis of botulism was confirmed by demonstration and typing of toxin. Although other techniques, in particular ELISA, are currently being evaluated and appear promising, ${ }^{24}$ specific seroneutralisation in mice can be used for various types of sample and is the standard reference method. As botulism may be misdiagnosed as myasthenia gravis, specific seroneutralisation in mice can be complicated by pyridostigmine treatment of patients. ${ }^{27}$ Toxaemia is generally demonstrated in c. $50 \%$ of cases $^{17}(52 \%$ in our series). Toxaemia persisted for 5-43 days after diagnosis in some cases, within which time patients had recovered from the disease. No tests were done for circulating antibodies against botulinum toxin. Toxaemia has been reported to persist for a variable time - up to several weeks ${ }^{17}$ - raising the question of chronic carriage of the organism or of re-infection. This finding does not appear in reports from the USA, possibly due to treatment of patients with antitoxin or to differences between toxin types-non-proteolytic type B in France but proteolytic type A and B in the USA. Culture for C. botulinum in stool samples may be useful and is positive in $c .70 \%$ of cases. ${ }^{28}$

Botulism is a serious intoxication that is potentially lethal. The course of the disease is often complicated by infections of the oropharhynx or respiratory tract, and by paralysis of respiratory muscles which may require assisted ventilation. ${ }^{22,29}$ Cases of botulism caused by type $\mathrm{A}$ or $\mathrm{E}$ toxin seem to be more severe than those caused by type B. However, although the severity of disease and the number of complications are greater with type A toxin, there is no difference between toxins A and B in terms of mortality ${ }^{2}$. Disease caused by type $\mathrm{E}$ toxin has a reputation for being particularly serious; $53 \%$ of deaths reported by Wainwright et $a .^{2}{ }^{2}$ were due to type $\mathrm{E}$ botulism, but $73 \%$ of the cases in that study were due to type E. In France, two fatal cases were reported in 1987 and 1988 with type B C. botulinum. ${ }^{7}$ The prognosis of botulism may be also influenced by the length of the incubation period $^{2}$ and-although these factors are not universally accepted-by age, race (the disease may be more severe in Asian people), early involvement of the third cranial nerves and paralysis of the respiratory muscles. ${ }^{22,23}$ There were no deaths in our series; this may be due to the frequency of the mild forms of the disease (reflected by the unusually long incubation period), and the usually good prognosis of type B botulism in France.

Approaches to the treatment of botulism remain debatable. All authors agree that symptomatic care is essential, including artificial tears, spraying and humidification of the oropharynx and airways, and feeding by gastric tube or parental nutrition. Specific treatment is more controversial, particularly in relation to the adequacy and effectiveness of serotherapy. The use of botulinum toxoid is of doubtful value for treating botulism, ${ }^{18}$ because the time required to achieve an immunological response is too long. Equine serum may be given parentally at $0.5 \mathrm{ml} / \mathrm{kg}$ (for type B, $1 \mathrm{ml}=250 \mathrm{IU}$ ). It should be reserved for severe forms of the disease in which it needs to be used at an early stage to be effective. ${ }^{17,30}$ However, waiting 
to determine whether a case is severe or mild before deciding to administer antiserum could compromise its usefulness; severity must be determined by simple clinical examination. The duration of treatment remains debatable; most authors advocate treating until there is no further progression of symptoms. ${ }^{20}$ Serotherapy may prevent progression of neurological symptoms and may shorten the time of respiratory distress and assisted ventilation in type E botulism. ${ }^{16}$ The level of circulating antitoxin measured after administration (in four patients) appeared to reduce the rate of circulating type A, B or E toxin..$^{30}$ There may not be any advantage in giving more than two doses of antitoxin. ${ }^{30}$ There is no evidence that it is necessary to clear circulating toxin in mild forms of the disease. The value of serotherapy in the intermediate or mild forms of type B botulism seen in France has not been established, particularly because the use of heterologous serum is not without risk.

Concern about serotherapy and its side effects led Cherrington and Ryan ${ }^{19}$ to propose, in 1968, the use of guanidine given orally at $10-35 \mathrm{mg} / \mathrm{kg}$ daily, in four doses. Guanidine antagonises the effects of botulinum toxin at the neuromuscular junction. They obtained beneficial results in 34 of 52 cases. ${ }^{19}$ The effectiveness

\section{References}

1. Centers for Diseases Control. Botulism in the United States 1897-1973. Handbook for epidemiologists, clinicians and laboratory workers. Atlanta, CDC. 1974.

2. Wainwright RB, Heyward WL, Middaugh JP, Hatheway CL, Harpster AP, Bender TR. Food-borne botulism in Alaska, 1947-1985: epidemiology and clinical findings. J Infect Dis 1988 ; 157 : 1158-1162.

3. Craig JM, Iida $\mathrm{H}$, Inoue $\mathbf{K}$. A recent case of botulism in Hokkaïdo Japan. Jpn J Med Sci Biol 1970; 23: 193-198.

4. Lecour H, Ramos MH, Almeida B, Barbosa R. Food-borne botulism. A review of 13 outbreaks. Arch Intern Med 1988; 148: $578-580$.

5. Hauschild A. Botulism in Canada: summary for 1984. Can Med Assoc $J$ 1985; 132: 1402

6. Pourtaghva M, Machoun A, Fatollahzadeh et al. Le botulisme en Iran. Med Mal Infect 1975; 5: 536-539.

7. Quenum B, Hubert B, Sebald M. Le Botulisme en 1987 et 1988. Bull Epidemiol Hebdomadaire 1989; 27 : 109-110.

8. Arnon SS, Midura TF, Clay SA, Wood RM, Chin J. Infant botulism. Epidemiological, clinical, and laboratory aspects. JAMA 1977; 237 : 1946-1951.

9. Morris JG, Snyder JD, Wilson R, Feldman RA. Infant botulism in the United States: an epidemiological study of cases occurring outside of California. Am J Public Health 1983; 73: $1385-1388$

10. MacDonald KL, Cohen ML, Blake PA. The changing epidemiology of adult botulism in the United States. Am J Epidemiol 1986; 124: 794-799.

11. Horwitz MA, Hughes JM, Merson MH, Gangarosa EJ. From the Center for Disease Control. Food-borne botulism in the United States. 1970-1975. J Infect Dis 1977; 136: $153-159$.

12. Merson MH, Dowell VR. Epidemiological, clinical and laboratory aspects of wound botulism. $N$ Engl J Med 1973; 289: 1005-1010.

13. MacDonald KL, Rutherford GW, Friedman SM et al. Botulism and botulism-like illness in chronic drug abusers. Ann Intern Med 1984; 102: 616-618.

14. Telzak EE, Bell EP, Kautter DA et al. An international outbreak of type $\mathrm{E}$ botulism due to uneviscerated fish. $J$ Infect Dis $1990 ; 161$ : 340-342.

15. Lund BM, Graham AF, George SM. Growth and formation of toxin by Clostridium botulinum in peeled inoculated of guanidine has been further established by clinical and pathophysiological data ${ }^{31-34}$ and by electromyography. Improvement is most notable in ocular muscles and less in respiratory muscles. ${ }^{33}$ As ocular symptoms are predominant in type B botulism, guanidine hydrochloride would appear to be of particular value in those cases. The side effects, which generally involve the gastrointestinal tract, are minor and disappear when the dose is reduced. However, French workers remain very reluctant to use guanidine in botulism. Our experience in the present study favours the use of guanidine in intermediate or mild forms of the disease, which are the most frequent forms in France, combined with symptomatic treatment. Serotherapy should be reserved for severe forms of the disease, but serotherapy is used generally in France essentially for medico-legal or historical reasons, in the absence of any studies that show its lack of effectiveness.

New methods of treatment are still to be evaluated -anti-cholinesterase treatment with 3,4-diaminopyridine does not appear to be effective $;{ }^{28}$ the high mol. wt of the toxin does not allow its elimination by dialysis; but plasma exchange probably deserves to be evaluated in severe forms of botulism.

vacuum-packed potatoes after a double pasteurization and storage at $25^{\circ} \mathrm{C}$. J Appl Bacteriol 1988; 64: 241-246.

16. Blettery B, Soichot P, Virot C, Lorecerie B, Hillon P. Le botulisme de type E: deux observations récentes. Nouv Presse Med 1982; 11: 1131-1133.

17. Fourrier A, Delmer M, Wattel F, Furon D, Mouton Y. Cas récents de botulisme dans le nord de la France. A propos de 26 observations (1962-1971). Rev Med 1972; 40: 2615-2627.

18. Galazka A, Rymkiewicz D, Aleksandrowicz J. Immunological response to Clostridium botulinum toxin. J Clin Microbiol 1988; 26 : 1250-1251.

19. Cherington M, Ryan DW. Botulism and guanidine. $N$ Engl $J$ Med 1968; 278: 931-933.

20. Hughes JM, Blumenthal JR, Merson MH, Lombard GL, Dowell VR, Gangarosa EJ. Clinical features of types A and B food-borne botulism. Ann Intern Med 1981 ; 95: 442-445.

21. Lewis SW, Pierson DJ, Cary JM, Hudson LD. Prolonged respiratory paralysis in wound botulism. Chest 1979; 75 : 59-61.

22. Terranova W, Palumbo JN, Breman JG. Ocular findings in botulism type B. JAMA 1979; 241 : 475-477.

23. St-Louis ME, Peck SHS, Bowering D et al. Botulism from chopped garlic: delayed recognition of a major outbreak. Ann Intern Med 1988; 108: 363-368.

24. Dezfulian M, Hatheway CL, Yolken RH, Barlett JG. Enzymelinked immunosorbent assay for detection of Clostridium botulinum type A and type B toxins in stool samples of infants with botulism. J Clin Microbiol 1984; 20:379-383.

25. Graf WD, Hays RM, Astley SJ, Mendelman PM. Electrodiagnosis reliability in the diagnosis of infant botulism. $J$ Pediatr 1992; 120: 747-749.

26. Davis LE, Johnson JK, Bicknell JM, Levy H, McEvoy KM. Human Type A botulism and treatment with 3,4diaminopyridine. Electromyogr Clin Neurophysiol 1992; 32: 379-383.

27. Horwitz MA, Hatheway CL, Dowell VR. Laboratory diagnosis of botulism complicated by pyridostigmine treatment of the patient. A method for selectively removing interfering substances from clinical specimens. Am J Clin Pathol 1976; 66: 737-742.

28. Dowell VR, McCroskey LM, Hatheway CL, Lombard CL, Hughes JM, Merson MH. Coproexamination for botulinal toxin and Clostridium botulinum. A new procedure for 
laboratory diagnosis of botulism. JAMA 1977; 238: 1829-1832.

29. MacDonald KL, Spengler RF, Hatheway CL, Hargett NT, Cohen ML. Type A botulism from sauteed onions. Clinical and epidemiologic observations. JAMA 1985; 253: 1275-1278.

30. Hatheway CH, Snyder JD, Seals JE, Edell TA, Lewis GE. Antitoxin levels in botulism patients treated with trivalent equine botulism antitoxin to toxin types A, B and E. $J$ Infect Dis 1984; 150: 407-412.
31. Robineau M, Modai J, Laffay J, Domart A. Note préliminaire sur le traitement du botulisme par la guanidine. A propos d'un cas. Presse Med 1971; 79: 1169-1171.

32. Oh SJ, Hasley JH, Briggs DD. Guanidine in type B botulism. Arch Intern Med 1975; 135: 726-728.

33. Puggiari $\mathbf{M}$, Cherington $\mathbf{M}$. Botulism and guanidine. Ten years later. JAMA 1978; 240: 2276-2277.

34. Kaplan JE, Davis LE, Narayan V, Koster J, Katzenstein D. Botulism, type A and treatment with guanidine. Ann Neurol $1979 ; 6: 69-71$. 